\title{
DELIETRAS
}

\section{A formação do nominal nas construções com o verbo leve "fazer", à luz da Morfologia Distribuída}

\section{The formation of the nominal in constructions with the light verb "fazer", in the light of Distributed Morphology}

\author{
Daniela Almeida Alves ${ }^{1}$ \\ Maria Cristina Vieira de Figueiredo Silva ${ }^{2}$
}

\begin{abstract}
RESUMO: Neste artigo, analisamos construções com o verbo leve "fazer", mais precisamente os fatores que contribuem para que essas construções, no português, denotem diferentes leituras. Assumimos que o processo de formação do nominal com que o verbo se combina tem influência nas leituras denotadas. Na investigação, consideramos a proposta de formação de palavras por "fases" da Morfologia Distribuída (HALLE; MARANTZ, 1993; MARANTZ, 2001, 2007, 2013; ARAD, 2003; EMBICK, 2010). Argumentamos que, quando o nominal é formado diretamente da raiz, a leitura da construção é idêntica à da construção com verbo pleno correspondente e, quando é um deverbal, a leitura é distinta, considerando-se os traços contidos na projeção aspectual que domina o categorizador verbal.
\end{abstract}

Palavras-chave: Verbo leve “fazer”; Nominalização; Morfologia Distribuída; Fases.

ABSTRACT: In this paper, we analyze constructions with the light verb "fazer" (to make), more precisely the factors that contribute to that these constructions, in Portuguese, denote different readings. We assume that the process of formation of the nominal with which the verb is combined influences the denoted readings. In the research, we consider the proposal of word formation by phases of Distributed Morphology (HALLE; MARANTZ, 1993; MARANTZ, 2001, 2007, 2013; ARAD, 2003; EMBICK, 2010). We argue that when the nominal is formed directly from the root, the reading of the construction is identical to that of the construction with corresponding heavy verb and, when it is a deverbal, the reading is distinct, considering the traces contained in the aspectual projection that dominates the verbal categorizer.

Keywords: Light verb "fazer" (to make in English); Nominalization; Distributed Morphology; Phases.

\section{Introdução}

\footnotetext{
${ }^{1}$ Mestre (2016); Doutoranda pelo Programa de Pós-Graduação em Língua e Cultura - UFBA e bolsista CAPES. E-mail: danisagitariana@hotmail.com

2 Doutora em Linguística, Professora Adjunta III do ILUFBA e do PPGLinC-UFBA. E-mail: macrisfig@uol.com.br
} 
Construções com verbo leve (CVLs), de acordo com a literatura linguística, são constituídas por um verbo, denominado de leve (VL), combinado com um elemento de natureza nominal $(\mathrm{N})$, como em (1a), ou acrescida de um elemento preposicionado, quando requerido, como em (1b).
a. Michelly fez um passeio divertidíssimo. ${ }^{3}$
b. A Apple fez um reajuste nos preços do iPhone. ${ }^{4}$

Desse modo, a estrutura das CVLs, no português, é definida pela combinação de um VL e N, no mínimo, ou por três elementos, VL N PP5 . No entanto, essa estrutura não é a mesma em todas as línguas naturais, uma vez que não só a ordem dos elementos, tendo em vista a posição do núcleo em relação a seus argumentos, mas também a combinação dos elementos nessas construções variam entre as línguas. Por exemplo: na língua japonesa, uma língua de núcleo final, a estrutura é N + V (GRIMSHAW; MESTER, 1988), como em (2a); na língua urdu, falada no sul asiático, além da estrutura $\mathrm{N}+\mathrm{V}^{6}$, é bastante recorrente a estrutura V + V (BUTT, 2003), como no exemplo em (2b), em que apenas a segunda forma carrega morfologia verbal, daí ser considerada VL. Assim como no português, nas demais línguas românicas, a estrutura é V + N (ALBA-SALAS, 2002), conforme exemplo do italiano em $(2 c)$ :

$$
\begin{aligned}
& \text { a. John-ga Bill-to HANASHI-o shiteiru. } \\
& \text { John-ga Bill-com HANASHI-o suru-Gerúndio (fazendo isso) }{ }^{7} \\
& \text { "John está conversando com Bill."» }
\end{aligned}
$$

(Adaptado de GRIMSHAW; MESTER, 1988, p. 210)

b. nadya $=$ ne makan bana di-ya.

Nadya.F.Sg=Erg casa.M.Nom fazer dar-Perf.M.Sg

"Nadya fez uma casa (completamente, para outra pessoa)."

\footnotetext{
${ }^{3}$ Disponível em: <http://gshow.globo.com/RPC/Plug/noticia/>. Acesso em: 02/08/2015.

${ }^{4}$ Disponível em: <https://pt-br.facebook.com/MGTUR/posts/776491722419469>. Acesso em: 23/05/2015.

${ }^{5} \mathrm{PP}=$ Prepositional Phrase $=$ Sintagma Preposicional.

${ }^{6} \mathrm{O}$ urdu é uma língua SOV com uma ordem de palavras bastante livre (BUTT, 2003).

${ }^{7}$ De acordo com os autores, shiteiru é uma das formas do verbo suru, que é composto pela raiz shi e a marca de gerúndio teiru.

${ }^{8}$ Nem sempre a tradução corresponde a uma CVL, como no português.
} 
(Adaptado de BUTT, 2003, p. 2)

c. Monica farà una telefonata a Eva.

Monica-Nom farà-Fut una telefonema-Acc a Eva-Dat

"Mônica fará uma telefonema para Eva."

(Adaptado de ALBA-SALAS, 2002, p. 268)

No japonês, conforme Grimshaw e Mester, o VL é suru (fazer), que ocorre, em (2a), em sua forma de gerúndio, shiteiru. Em (2b), em que se observa uma construção com duas formas verbais, de acordo com Butt (2003), o VL é o que se apresenta na forma flexionada, ou seja, o di. Nessa língua, segundo a autora, o VL está sempre associado a algumas delimitações semânticas como força, volição ou beneficiário, conforme ilustrado em (2b). Já em (2c), segundo Alba-Salas (2002), o VL é farà.

A definição de VL não é um consenso na literatura. É comum caracterizá-lo como semanticamente vazio e portador das informações gramaticais: tempo, modo, número, pessoa e aspecto. Porém, Butt (2003), Fortunato (2009) e Duarte et al. (2010) assumem que o VL não é um elemento meramente gramatical e o definem como semanticamente incompleto, no sentido de que contribui com informação de aspecto lexical para a predicação conjunta. Segundo Moura Neves (1996), um VL não pode ter como argumento interno um nome referencial com interpretação específica e essa característica contribui para a identificação das CVLs. Os exemplos em (3) registram os dois comportamentos do verbo fazer.

(3) a. Ele tratou de criar mais uma polêmica para sua extensa coleção: fez um gesto que é chamado de La Quenelle na comemoração de um dos seus dois gols. ${ }^{9}$

b. Delegacia da Receita Federal do Brasil de Lages fez a destruição de mercadorias apreendidas. ${ }^{10}$

A construção, em (3a), não é de verbo leve, mas de verbo pleno, uma vez que o nome que acompanha o verbo é mais referencial e específico, por ser identificável tanto pelo falante quanto pelo ouvinte (CYRINO; DUARTE; KATO, 2000). Além disso, embora o argumento interno, um gesto que é chamado de La Quenelle, seja introduzido por um artigo indefinido,

\footnotetext{
${ }_{9}^{9}$ Disponível em: <http://trivela.uol.com.br/anelka-la-quenelle-e-o-que-isso-tem-ver-com-nazismo/>. Acesso em: 20/06/2015.

${ }^{10}$ Disponível em: $<$ http://saojoaquimonline.net/>. Acesso em: 10/05/2015.
} 
considerado uma das principais características de um nome não referencial no português, como sugere a tradição gramatical, a sua modificação por uma oração adjetiva não deixa dúvidas quanto à sua referencialidade, visto que contribui para a construção do valor referencial do N. Já em (3b), de acordo com Moura Neves (1996), temos uma CVL, e embora o argumento interno da construção seja introduzido por um artigo definido, considerado pela tradição gramatical como denotador de referencialidade, sua presença não foi o suficiente para bloquear a formação da construção, isso porque não possui alto grau de referencialidade no português. Conforme a autora, quanto mais referencial é o nome, menor será sua contribuição para a composição do esquema de predicado. Dessa forma, temos, no português, CVLs que ocorrem com DPs ${ }^{11}$ nus ou encabeçados por artigos indefinidos ou definidos. A referencialidade deve ser identificada a partir de recursos gramaticais de referenciação ou do contexto discursivo.

Sobre o N, o argumento interno da CVL tem-se apontado como o responsável pela significação dessas construções, deu um beijo $=$ beijar, fez uma reforma $=$ reformar (MOURA NEVES, 1996; ALBA-SALAS, 2002; SCHER, 2004; Autor, 2016), porém o N nem sempre corresponde a um verbo pleno (deu sono, fez sucesso). Quanto à sua estrutura, pode ocorrer diretamente da raiz (Nprimitivo) ${ }^{12}$ ou a partir de uma palavra (Nderivado), como se vê em (4) e em (5), respectivamente.
a. Pareço legal, mas já fiz medo a uma criança. ${ }^{13}$
b. Fiz o aperto da hélice do modelo Giant. ${ }^{14}$

a. Pastora faz pregação voluntária em escolas do caso "Charlie, Charlie". ${ }^{15}$

b. Chavez já alterou o nariz, fez um reajustamento no maxilar e clareou a pele. $^{16}$

\footnotetext{
${ }^{11}$ DP - Determiner Phrase = Sintagma Determinante

12 Seguindo as argumentações de Basílio (1980, p.78) e Rocha (2008, p.181) sobre processos de formação de palavras e o problema que envolve a formação de palavra considerada regressiva, estão incluídos, entre os Nprimitivos, os nomes considerados regressivos pela tradição gramatical.

13 Disponível em: <http:/tenho-que-dormir.tumblr.com/post/43894634416/pare\%C3\%A>. Acesso em: $02 / 06 / 2015$.

${ }^{14}$ Disponível em:

$<$ https://www.facebook.com/permalink.php?story_fbid=1112513992095220\&id=494964803850145>. Acesso em: 10/10/2015.

${ }^{15}$ Disponível em: <http://www.portaldoholanda.com.br/brasil/>. Acesso em: 06/06/2015.

${ }^{16}$ Disponível em: <http://www.tvi24.iol.pt/acredite-se-quiser>. Acesso em: 09/05/2015.
} 
Observando os exemplos em (4) e (5), verificam-se algumas peculiaridades, ao se comparar as CVL à sua contraparte plena correspondente. Em (4), a leitura expressa pelas CVLs é de eventualidade realizada completamente, idêntica à eventualidade expressa pelas construções com os verbos plenos correspondentes amedrontei e apertei. Já em (5), a leitura denotada pelas CVLs é de eventualidade aumentativizada, isto é, realizada de forma que ultrapassa a completude, seja no que diz respeito à duração, seja com relação à intensidade do evento, conforme testes realizados e descritos na seção 2. Essas diferentes leituras suscitam a seguinte questão: assumindo que o N é o responsável pela significação das CVLs, as possíveis leituras estão prefiguradas na raiz, ou se devem à estrutura do $\mathrm{N}$, ou ainda ao processo de formação de N?

Sob a hipótese de que as diferentes leituras estão relacionadas aos tipos de formação do $\mathrm{N}$ (de raiz ou de palavra), levamos em consideração os pressupostos da Morfologia Distribuída (HALLE; MARANTZ, 1993), mais precisamente a sua proposta de formação de palavras por fases (MARANTZ, 2001, 2007; ARAD, 2003; EMBICK, 2010). ${ }^{17}$

O texto está organizado da seguinte maneira. Em 1, apresentamos as principais características das CVLs com fazer; na seção 2, os resultados dos testes aplicados e as leituras denotadas pelas CVLs; na seção 3, a proposta de análise, de acordo com a Morfologia Distribuída (MD), considerando-se a hipótese assumida. Por fim, as considerações finais.

As construções com o verbo leve "fazer"

Em sua versão plena, o verbo fazer significa produzir através de determinada ação; construir; confeccionar; preparar (HOUAISS, 2001), ou seja, expressa o sentido de dar existência/forma a algo.

O verbo fazer pleno é considerado como transitivo de dois argumentos: o argumento externo e o argumento interno. Compõe uma predicação que pressupõe uma entidade controladora (agente e animada) a qual pode determinar se um estado de coisas ocorrerá ou

\footnotetext{
${ }^{17}$ Como se verá adiante, o referencial teórico adotado demonstra explicar melhor o contraste entre Nderivados e verbos plenos, do que a identidade entre Nprimitivos e verbos plenos. Dessa forma, salientamos que o que formos propor como explicação para CVLs + Nprimitivo é ainda muito preliminar e, portanto, será revisto posteriormente.
} 
não, e uma entidade controlada (inanimada/concreta) que muda de estado ou passa a existir sob a ação daquela, como em $(6)^{18}$.

(6) a. Pedro fez uma casa.

b. Ana fez um poema.

Nas sentenças em (6), cujo valor é construção/preparação de algo ou dar existência/forma a algo, os sujeitos Pedro e Ana atuam intencionalmente para dar forma aos objetos uma casa e um poema, que não existiam e passaram a existir por causa da ação dos agentes. Desse modo, os papéis semânticos dos componentes da construção são: agente, para o argumento externo animado; e tema para o objeto concreto. Além disso, segundo Gonçalves et al. (2010), fazer pleno pode apresentar um argumento interno beneficiário facultativo, que ocorre sob a forma de sintagma preposicional, como em (7).

O Pedro fez uma casa na árvore (às / para as crianças).

(GONÇALVES et al., 2010, p. 3)

Embora os autores proponham que seja um argumento interno, consideramos o PP, em (7), seguindo Pylkkänen (2002), um aplicativo, adjungido ao $\mathrm{VP}^{19}$. Dessa forma, assumimos que fazer requer apenas um argumento interno.

As sentenças com fazer pleno, em (6) e (7), conforme se observa, são dinâmicas e requerem um argumento interno tema que denota uma entidade. Essas sentenças podem ser definidas em termos de um conjunto de traços [+ dinâmico], [+ durativo] e [+ télico $]^{20}$, e se definem como construções do tipo accomplishment ${ }^{21}$, que exprimem um evento culminado.

Quanto à versão leve do verbo fazer, em comum com a versão plena, ela satisfaz a condição morfossintática de se flexionar em tempo, modo, número e pessoa. Em

\footnotetext{
${ }^{18}$ Exemplos sem referência ou fonte são sugeridos por nós, para este artigo.

${ }^{19} \mathrm{VP}$ - Verbal Phrase = Sintagma Verbal

${ }^{20}$ Traços que permitem a identificação do aspecto lexical das formas verbais, conforme Smith (1997).

21 É uma das classes aspectuais Vandlerianas. Segundo Vendler (1967), as classes aspectuais são quatro: accomplishment, que expressa eventualidade dinâmica, durativa, e possui ponto final determinado; achievement, que expressa eventualidade dinâmica, pontual, e possui ponto final determinado; atividade, que expressa eventualidade dinâmica, durativa, e não possui ponto final determinado; e estativa, que expressa eventualidade não dinâmica e durativa, e não possui ponto final determinado. Smith (1997) acrescenta uma quinta classe, a dos semelfactivos, que expressam eventualidade dinâmica e instantânea, que se repete iterativamente.
} 
contrapartida, fazer leve não denota o sentido de construir, dar existência/forma a algo, pode descrever um evento, que, como em (8a), corresponde à forma plena visitar, como também uma entidade, festa, em (8b).

a. Francisco fez uma visita ao pai.

b. Pedro fez uma festa ao saber que foi aprovado no concurso.

Em (7) e (8) se observa correspondência de papel semântico tema entre as duas versões de fazer, no entanto, enquanto na versão plena esse verbo somente se combina com um $\mathrm{N}$ entidade, sua versão leve pode se combinar com um $\mathrm{N}$ denotador de entidade ou com um $\mathrm{N}$ expressando evento. Além disso, CVLs com fazer podem ocorrer não só com sujeito agente, mas também causativo (ALBA-SALAS, 2002; GONÇALVES et al, 2010), como se verifica em (9).

(9) 'Uma nuvem funil' fez estragos na zona rural de Congonhal (MG). ${ }^{22}$

Em termos de traços, Duarte et al. (2010) assumem que fazer leve é diferente da sua versão plena por ser subespecificado para alguns traços e propõem que esse VL apresenta traços aspectuais como [+dinâmico], [ \pm durativo], [-instantâneo]. Tendo em vista essas propriedades semânticas, segundo os autores, fazer leve impõe restrição quanto ao nome com o qual se combina, aceitando apenas nomes que denotam processo e processo culminado ${ }^{23}$, como se observa em (10).

(10) a. A Maria fez uma caminhada.

b. O João fez uma leitura do artigo.

c. *O João fez uma vida.

d. *O João fez um espirro.

(DUARTE et al., 2010, p. 2)

\footnotetext{
22 Disponível em: http://pousoalegre.net/noticia/2016/06/fenomeno-parecido-com-tornado-faz-estragos-emcongonhal/>. Acesso em: 02/07/2016.

${ }^{23}$ Processo, processo culminado, pontualidade, culminação e estado, nas terminologias de Vendler (1967) e Smith (1997), correspondem respectivamente a verbos de atividade, accomplishment, semelfactivo, achievement e estado.
} 
Conforme Duarte et al. (2010), em (10), o VL fazer não se combina com nomes que expressam eventualidade estativa, como em (10c), nem pontuais, como em (10d). No entanto, nos dados coletados, verificamos CVLs em que fazer leve ocorre combinado com nomes que derivam de bases que denotam pontualidade, como em (11):

(11) a. Fernanda Rodrigues fez uma entrada na passarela usando óculos. ${ }^{24}$

b. Susana Vieira fez uma chegada triunfal ao ensaio da Grande Rio. ${ }^{25}$

c. A Caixa Econômica ainda não fez o desligamento de nenhuma casa lotérica com a empresa. ${ }^{26}$

Como se verifica em (11), o evento denotado pela CVL é pontual, ou seja, sua realização não se prolonga temporalmente. É compatível com a expressão temporal às $\mathbf{X}$ tempo, mas não com a expressão durante $\mathbf{X}$ tempo. Além disso, verifica-se que é [+ dinâmico] e [+ télico].

Resumindo, fazer leve possui as seguintes características:

- não denota o sentido de construção ou de dar existência ou forma a algo;

- não preserva apenas o papel temático de agente para o seu argumento externo, podendo ocorrer também com um causativo;

- preserva o papel temático de tema para seu objeto direto, que pode ser denotador de entidade ou de evento;

- possui os traços aspectuais: [+ dinâmico], [ \pm durativo], [- instantâneo] e [+ télico].

Sobre as leituras das CVLs: testes de verificação de completude

Para realizar esta pesquisa, coletamos, em sites de língua portuguesa, 489 ocorrências de CVLs com o verbo fazer combinado com $\mathrm{N}$ de diferente constituição fazer + Nprimitivo e fazer + Nderivado constituídos pelos nominalizadores -ção, -mento e -ada, com a ajuda da ferramenta de busca Google. A busca das construções nos sítios digitais ocorreu a partir das formas pretéritas de $1^{\mathrm{a}}$ e $3^{\mathrm{a}}$ pessoas (e.g., fiz/fizemos uma reforma; fez/fizeram uma correção),

\footnotetext{
${ }^{24}$ Disponível em: <http://www.purepeople.com.br/noticia/>. Acesso em: 03/04/2015.

${ }^{25}$ Disponível em: < http://diversao.terra.com.br/carnaval/rio-de-janeiro/celebridades $>$. Acesso em: 20/07/2015.

26 Disponível em: <http://clicrbs.com.br/especial/sc/qualidade-de-vida-sc/19,0,1043236,> Acesso em: $24 / 07 / 2015$.
} 
por serem as formas mais recorrentes. Eventualmente encontrávamos CVLs com a forma verbal no presente, no infinitivo, no futuro etc.

No intuito de estabelecer comparações, fizemos uma análise quantitativa dos dados, cujos resultados demonstraram que o VL fazer é mais produtivo com Nderivado: do total de ocorrências coletadas, 221 foram com N-ção, 111 com N-mento e 18 com N-ada, e 139 com Nprimitivo, conforme sumarizado no Quadro 1.

Quadro 1: Distribuição das ocorrências, segundo os processos de formação e do sufixo nominalizador do $\mathrm{N}$ das CVLs do corpus

\begin{tabular}{|c|c|c|c|c|}
\hline \multirow{2}{*}{ Nprimitivo } & \multicolumn{3}{|c|}{ Nderivado } & \multirow{2}{*}{ Total } \\
\cline { 2 - 4 } & - ção & - mento & - ada & 489 \\
\hline 139 & 221 & 111 & 18 & 4 \\
\hline
\end{tabular}

Fonte: Elaborado pelas autoras.

Analisando as construções coletadas, tivemos a intuição de que as CVLs com o verbo fazer, considerando-se as estruturas possíveis do elemento nominal, expressam diferentes leituras quanto à completude da eventualidade. Com a finalidade de comprovar ou refutar tal intuição, aplicamos testes de identificação de completude a 40 indivíduos que não fossem estudantes de Letras nem professor da área, a fim de termos uma amostra mais confiável. A aplicação dos testes foi realizada por meio digital. As fichas com as questões foram enviadas por e-mail aos indivíduos de nossas redes de relações, e para cada indivíduo foram enviadas 2 ou 3 fichas, conforme a possibilidade de formação com Nprimitivos e Nderivados. Cada ficha constava de duas questões. Na primeira, constituída de um par de sentenças, como em (12), uma CVL e uma construção com verbo pleno correspondente, os informantes deveriam verificar se os eventos expressos pelas construções apresentadas teriam significados diferentes, marcando sim ou não.
(12) ( ) Fiz um apelo às autoridades.
( ) Apelei às autoridades.
( ) Fez uma chegada triunfal.
( ) Chegou triunfalmente.
( ) Fiz uma arrumação na casa.
( ) Arrumei a casa.
( ) Fez detalhamento da proposta.
( ) Detalhou a proposta 
Na segunda questão, cuja resposta era condicionada à resposta sim à primeira questão, dever-se-ia verificar o nível (em números) de completude de cada par proposto na questão anterior. Os níveis propostos estão exemplificados em $(13)^{27}$.

(13) (1) Para a sentença que expressa um evento realizado de forma incompleta, rápida e descuidada.

(2) Para a sentença que expressa um evento realizado de forma completa, cuidada, em tempo normal e sem agitação;

(3) Para sentença que expressa um evento realizado de forma que ultrapassa a completude, ou seja, realizada de forma muito cuidadosa, demorada e intensificada;

Salientamos que as CVLs selecionadas para constituir os testes foram escolhidas dentre os dados coletados em sites da internet. Além disso, nos testes, não controlamos a escolaridade, pois acreditamos que o processo de escolarização não interfere no significado das CVLs, bem como não controlamos a faixa etária do informante, tendo em vista que não se tinha como objetivo verificar mudança no uso dessas construções.

Os resultados dos testes confirmaram a hipótese de que há leituras diferentes, de acordo com o tipo do $\mathrm{N}$ presente na construção: i) VL + Nprimitivo parece expressar leitura idêntica à da construção com verbo pleno, ou seja, expressa um evento/uma ação realizada de forma completa, leitura apontada por $28(70 \%)$ dos 40 informantes testados e; ii) fazer + Nderivado parece expressar leitura diferente à da construção com o verbo pleno, diferença apontada por 34 (85\%) dos 40 indivíduos testados.

Os resultados também apontam que, a depender do sufixo constitutivo do $\mathrm{N}$, a leitura pode ser distinta, principalmente quando ocorre a combinação fazer +- ada. Quanto às CVLs fazer $+\mathbf{N}$-ção, dos 34 informantes que responderam, 30 identificaram que sua leitura, tendo em vista a completude do evento, corresponde ao nível 3, o que significa que essas CVLs expressam uma eventualidade realizada de forma que ultrapassa a completude, ou seja, o evento pode ter sido realizado de forma mais cuidadosa, com maior duração e com mais

\footnotetext{
${ }^{27}$ Para conhecer melhor os testes aplicados, ver Autor (2016). Por ora, apresentamos algumas das construções utilizadas nos testes e as instruções para responderem.
} 
intensidade, se comparado à eventualidade expressa pela construção com o verbo pleno correspondente. As CVLs fazer $+\mathbf{N}$-mento, também foram interpretadas por 28 dos 34 respondentes como denotadoras de um evento realizado de forma demorada e bastante intensificada (nível 3). Já para as CVLs fazer $+\mathbf{N}-\mathbf{a d a}$, dos 34 informantes testados 14 responderam que a eventualidade expressa é compatível com o nível 2, ou seja, completa, porém menos demorada e intensificada que as construções cujo elemento nominal é formado pelos sufixos -ção e -mento e 17 reconheceram que expressa o máximo, o nível 3, o que parece ser possível se essa leitura for acompanhada por entonação acentuada.

Sobre as respostas diferentes das supracitadas, não foi possível contabilizar, pois não houve respostas coincidentes. Foram marcados níveis diferentes para ambos os tipos de CVLs (com Nprimitivo e com Nderivado), além de alguns informantes não terem respondido ao teste, talvez por não terem entendido a pergunta ou por terem considerado outras interpretações.

Resumindo, conforme a definição atribuída a cada nível e as respostas obtidas, verificamos que a leitura denotada pelas CVLs com fazer + Nderivado é de eventualidade aumentativizada, sobretudo quando os Ns são formados pela adição dos sufixos -ção e mento. Já CVLs com fazer $+\mathbf{N}-$ ada também expressam completude ampliada, quando comparadas à construção com verbo pleno correspondente (leitura feita por 17 informantes), porém menos intensa que nas construções envolvendo -ção e -mento, uma vez que 14 do total de 34 respondentes marcaram como denotadoras de eventualidade completa, assim como as CVLs com Nprimitivo. O interessante a se observar é que nenhum dos informantes atribuiu o nível 1 às CVLs com fazer $+\mathbf{N}-\mathbf{a d a}$, o que significa que não as interpretam como denotadoras de eventualidade diminutivizada, como aponta Scher (2004), para as CVLs com a combinação dar $+\mathbf{N}$-ada. Isso nos levar a pensar que o VL fazer pode estar interferindo nas leituras, como discutirei adiante.

Tendo em vista que a diferença semântica entre os dois tipos de CVL diz respeito à duração e à dinamicidade da eventualidade expressa, traços que permitem a leitura de aspecto lexical e que dizem respeito à categoria verbal, sugerimos, preliminarmente ${ }^{28}$, que essas diferentes leituras podem estar relacionadas à presença ou ausência desses traços no elemento nominal, ou ainda à questão do acesso local e não local das informações, o que está relacionado à alocação das fases em determinado ponto da estrutura.

\footnotetext{
${ }^{28}$ Isso porque estamos em fase de ampliação da pesquisa, buscando mais evidências em favor da proposta.
} 
Nas CVLs em que ocorre um Nprimitivo, os traços duração e dinamicidade não estão presentes no elemento nominal, visto ter sido gerado diretamente da raiz, segundo os pressupostos da Morfologia Distribuída (MARANTZ, 2001, 2007; ARAD, 2003), portanto, N não possui esses traços. Por outro lado, nas construções em que ocorre um Nderivado, o $\mathrm{N}$ é formado a partir de um verbo que, por sua vez, projeta uma camada aspectual na estrutura interna do N (AUTOR, 2013), logo, os traços duratividade e dinamicidade estão presentes na derivação, conforme se verifica nas representações em (19), na seção seguinte.

A formação do elemento nominal na Morfologia Distribuída

Nesta seção, apresentamos os pressupostos da Morfologia Distribuída (MD), que servem de suporte para nossa análise. A utilização dessa teoria se justifica, principalmente, por: i) assumir que as palavras são formadas no componente sintático e; ii) assumir que raízes, um primitivo na Lista A, são acategoriais, visto que pretendemos justificar que as diferentes leituras das CVLs com fazer são resultantes das fases por que passam o elemento nominal dessas construções durante seu processo de formação.

A MD é uma teoria morfológica não convencional. A característica essencial desse modelo decorre da eliminação do léxico como um componente gerativo e do armazenamento das informações distribuídas por três listas não computacionais, a saber: a) Lista A, que armazena os traços abstratos, que são manipulados pela sintaxe durante a derivação, e as raízes, que são acategoriais; b) Lista $\mathbf{B}$, que armazena os itens de vocabulário que se constituem de expressão fonológica dos morfemas abstratos; e c) Lista C, que armazena o significado idiossincrático da estrutura sintática (raiz + categorizador), sendo determinado por cada língua em particular.

No modelo da MD, toda computação é sintática, e com isso os mesmos princípios sintáticos, Merge (concatenar) e Move (mover), que determinam a combinação de palavras em sintagmas e sentenças, determinam a combinação de morfemas em palavras, caracterizando uma de suas principais propriedades Syntatic Structure all the way down (Estrutura sintática por toda a derivação).

De acordo com Marantz (2001, 2007, 2013), no modelo da MD, as raízes deixaram de ser previamente especificadas em um léxico pré-sintático, como verbo, nome e adjetivo, e 
passaram a ser primitivos sintáticos que carecem de especificação categorial, sendo associada a uma categoria lexical sintaticamente, por meio de sua combinação a um núcleo categorizador (e.g., v, $n$ ou $a$ ), que determina borda de fase no curso da derivação das palavras.

Para o autor, seguindo Chomsky (1999), fase é o resultado de um merge de itens que ocorre dentro de um domínio de localidade ${ }^{29}$. Após a formação de cada fase se dá o spell-out da construção para a forma lógica (LF), a qual recebe a interpretação associada, e para a forma fonética (PF), para a atribuição de material fonológico, como se observa na representação em (14).

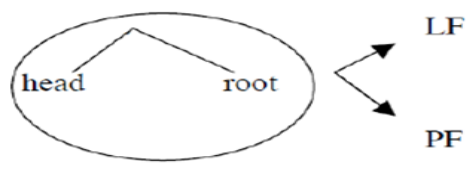

b.

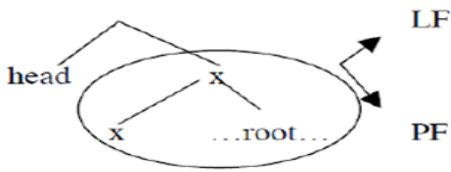

(MARANTZ, 2001, p. 7)

Segundo Marantz, em (14a), uma formação com apenas uma única fase, a raiz que é combinada a núcleos atribuidores de categoria é enviada às interfaces para as interpretações fonológica e semântica, e o significado da raiz no ambiente de $\mathbf{v}, \mathbf{n}$ e a é negociado na Lista C. Já em (14b), observa-se a combinação de outro núcleo categorizador à estrutura. Para esse núcleo mais alto, ficam visíveis apenas os traços dos núcleos funcionais localmente, mas não as propriedades da raiz que já foram enviadas para as interfaces. Todos os núcleos adicionados acima da primeira fase contribuirão composicionalmente para o significado resultante.

Arad (2003), partindo da proposta de Marantz (2001), apresenta uma distinção entre palavras derivadas de raiz, como em (14a), e palavras derivadas de palavras, i.e., de raiz, já categorizada, como em (14b), para argumentar que, no hebraico, as primeiras podem ter a elas atribuídas múltiplas e variadas interpretações, ao passo que as segundas têm sua interpretação vinculada à palavra formada na primeira fase da derivação. Ou seja, no segundo caso, (14b),

\footnotetext{
${ }^{29}$ Arad (2003, p. 747) sugere uma restrição de localidade sobre a interpretação de raízes: "roots are assigned an interpretation in the environment of the first category-assigning head with which they are merged. Once this interpretation is assigned, it is carried along throughout the derivation." (Raízes são interpretadas no domínio do primeiro núcleo categorial ao qual se associam. Uma vez definida essa interpretação, ela se mantém ao longo da derivação.) (Tradução nossa)
} 
haverá sempre uma dependência fonológica e semântica entre a palavra derivada e aquela da qual ela deriva.

Segundo Arad (2003), a maioria das raízes, no hebraico, consiste de consoantes segmentais, representadas, pela autora, por $\sqrt{ } \mathbf{C C C}$. Essas consoantes só serão pronunciadas quando inseridas em um padrão vocálico. Uma mesma raiz pode formar verbos e nomes de diferentes significados, embora compartilhem de um tipo de conceito comum, como em (15):

(15) $\sqrt{ } \operatorname{sgr}$
a. $\mathrm{CaCaC}(\mathrm{v})$
sagar
$\mathrm{v}$, 'to close' (fechar)
b. hiCCiC (v)
hisgir
$\mathrm{v}$, 'extradite' (extraditar)
c. hitCaCCeC (v) histager
$\mathrm{v}$, 'cocoon oneself' (proteger alguém)
d. $\mathrm{CeCeC}$ (n) seger
n, 'closure' (encerramento)
e. CoCCayim (n) sograyim
n, 'parentheses' (parênteses)
f. miCCeCet (n) misgeret
n, 'frame' (moldura)

(ARAD, 2003, p. 746)

Em (15), segundo a autora, estão exemplos de formações derivadas diretamente de raiz, por isso podem apresentar múltiplos significados a depender do ambiente em que irão figurar. No entanto, em alguns casos, há evidências na língua de que existem nomes formados diretamente de uma raiz e que servem de base para formar verbos, constituindo a segunda fase da derivação. A opção de assumir múltiplas interpretações não está disponível para esses casos, uma vez que a negociação do significado já foi fechada na primeira fase, como se observa em (16), em que o verbo formado a partir do nome misgeret (moldura), em (16a), só poderá significar misger (emoldurar), em (16b):

a.

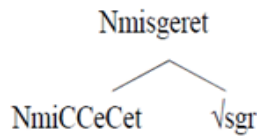

b.

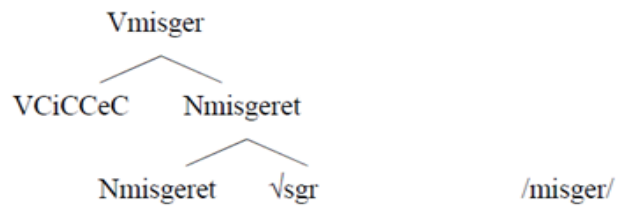

(ARAD, 2003,p.747) 
De acordo com Arad (2003), a presença de uma projeção nominal entre a raiz e a categoria verbal, em (16b), impede qualquer tipo de acesso do verbo às propriedades idiossincráticas da raiz, somente estando disponível para o restante da derivação o significado que se estabeleceu dentro da primeira projeção.

Tendo em vista a hipótese formulada para as diversas leituras das CVLs com fazer, sugerimos que a proposta de formação de palavras por fases, de Marantz $(2001,2007)$ e Arad (2003), é um modelo adequado para explicar essas diferentes leituras: quando o elemento nominal da construção é um Nprimitivo, ou seja, a raiz é combinada com o categorizador, constituindo-se apenas uma fase, a leitura final da CVL é semelhante à de uma construção como o verbo pleno, quando há correspondência, como em (17), que pode estar sendo identificada pela enciclopédia ou conhecimento de mundo do falante, processo que acontece na Lista C. Quando o elemento nominal é um Nderivado, ou seja, quando em sua formação é possível verificar mais de uma fase, a leitura final da construção é aumentativizada, conforme proposto na seção anterior, como se observa em (18).

(17) a. Síndico fez reforma na portaria e não cobrou taxa extra. ${ }^{30}$ (= reformou)

b. $\mathrm{O}$ morador fez um apelo às autoridades para que resolvam o esgotamento. ${ }^{31}$ (= apelou)

(18) a. Minha tia fez uma arrumação no meu quarto tão horrível. ${ }^{32}$

b. O sindicato fez detalhamento da proposta do governo para os agentes. ${ }^{33}$

c. Susana Vieira fez uma chegada triunfal ao ensaio da Grande Rio. ${ }^{34}$

Em (17), a leitura da CVL idêntica à da construção com verbo pleno correspondente se daria devido ao fato de a estrutura interna do $\mathrm{N}$ não apresentar uma projeção verbal, ou ainda em virtude de o acesso à informação ocorrer localmente, isto é, na primeira fase, resultando

\footnotetext{
${ }^{30}$ Disponível em: <http://www.sindiconet.com.br/7160/5/TiraDuvidas/Finanas/Sindico-fez-reforma-na-portariae-nao-cobrou-taxa-extra-e-nem-fez-Assembleia-pode-ser-feito-assim>. Acesso em: 20/04/2015.

${ }^{31}$ Disponível em: < http://www.taperoa.com/morador-faz-apelo-as-autoridades-para-que-resolvam-esgotamentosanitario/>. Acesso em: 23/ 03/2015.

${ }^{32}$ Disponível em: <https://twitter.com/robertaesp0sito/status/579404285533921280>. Acesso em: 10/06/2015.

${ }_{33}^{33}$ Disponível em: <http://jenisandrade.blogspot.com.br/>. Acesso em: 09/05/2015.

${ }^{34}$ Disponível em: $<$ http://diversao.terra.com.br/carnaval/rio-de-janeiro/celebridades $>$. Acesso em: 20/07/2015.
} 
em um significado convencional sem a participação de outros elementos. Já em (18), a leitura da CVL seria aumentativizada, pelo fato de a estrutura da nominalização exibir uma projeção verbal e, consequentemente, uma projeção aspectual, que contém traços associados às propriedades semânticas da eventualidade denotada (AUTOR, 2013), ou devido o acesso às informações não ocorrer localmente. Assim, parece que, no curso da derivação dos Ns, a ausência ou a presença de traços, bem como uma combinação diferente desses traços, como se observa nas representações em (19), ou ainda o acesso local e não local das informações, estariam interferindo na leitura das CVLs.
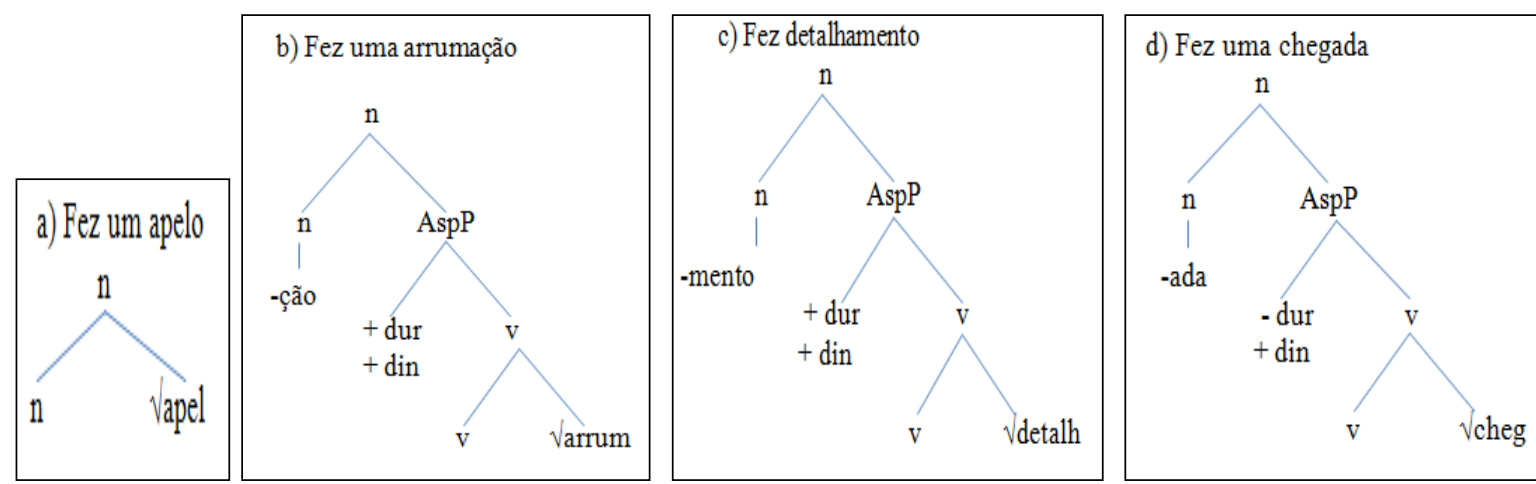

Como se nota, a categoria nominal, em (19a), que domina a raiz determina a fase e negocia o significado da raiz localmente, pois podem acessar as propriedades da raiz, já que a restrição de localidade para a interpretação da raiz foi respeitada e, além disso, não há uma camada aspectual em sua estrutura. Já em $(19 b$, c, d), a categoria verbal que domina a raiz também negocia o significado da raiz nesse contexto, ficando disponível para o restante da derivação apenas o significado que se estabeleceu dentro dessa projeção verbal. Ou seja, os Nderivados só poderão ver as propriedades do verbo já formado, não sendo capazes de acessar os traços das raízes, logo o acesso às informações não ocorre localmente. Assim, a semântica desses nomes depende de tudo o que foi adicionado acima da primeira fase. Por exemplo, além da projeção verbal, a estrutura do Nderivado exibe uma projeção funcional aspectual que contém um conjunto de traços abstratos (duratividade, dinamicidade e telicidade $)^{35}$ retirados da Lista A, que definem o elemento verbal. Essa projeção juntamente

\footnotetext{
${ }^{35}$ Geralmente abreviados por dur., din., e tel., respectivamente.
} 
com os traços, ativos ou não ativos, parecem estar contribuindo para as interpretações especiais que as nominalizações derivadas pelos sufixos -ção, -mento e -ada dão às CVLs com fazer.

O fato de as CVLs com $\mathrm{N}$-ada, conforme marcação dos informantes, não terem apresentado números expressivos para a leitura aumentativizada como as CVLs com $\mathrm{N}$-ção e $\mathrm{N}$-mento, leva-nos hipotetizar que a estrutura do $\mathrm{N}$-ada não tem ativo o traço de duração, como se nota em (19d). No entanto, como alguns dos respondentes consideraram a leitura aumentativizada para essas construções, os traços do VL fazer pode, também, estar contribuindo para as diferentes leituras. ${ }^{36}$

Como mencionado anteriormente, conforme Duarte et al. (2010), o VL fazer é [+ dinâmico], [ \pm durativo] e [- instantâneo], o que contribui para que CVLs com esse verbo + N -ção e N -mento, que, de acordo com Reis (2016), é [+ durativo], denotem leitura aumentativizada, ou seja, maior duração ou mais intensidade na realização do evento, visto que ambos não possuem ativo o traço de instantaneidade, e quando combinado com $\mathrm{N}-\mathbf{a d a}$, $[+ \text { instantâneo/ - durativo }]^{37}$, denotem leitura aumentativizada, porém em menor grau, já que ambos estariam compartilhando traços diferentes quanto à duração da eventualidade denotada. Em resumo, dependendo do sufixo, parece haver uma escala gradativa de aumentativização entre as CVLs com Nderivado, como se vê em (20).

$$
\begin{aligned}
& \text { fazer }+ \text {-ção }>\text { fazer }+- \text { mento }>\text { fazer }+ \text {-ada }>\text { fazer reforma/reformar } \\
& + \text { aumentativizada } \quad-\text { aumentativizada completa }
\end{aligned}
$$

Considerando as características do modelo da MD exposta nesta seção, salientamos que as generalizações que fizemos foram permitidas, devido ao fato de a sintaxe estar presente em toda a derivação e de as raízes serem acategorias.

\section{Considerações Finais}

Neste artigo, considerando-se os pressupostos da Morfologia Distribuída (MD), principalmente a proposta de que raízes são categorizadas no curso da derivação das palavras

\footnotetext{
${ }^{36}$ Formalização dessa operação está sendo pesquisada.

37 Propomos esse traço para as nominalizações em - ada, no entanto, estamos em fase de pesquisa, em busca de evidências para a proposta.
} 
no componente sintático, sugerimos que as diferentes leituras das CVLs com o verbo fazer, no português, estão relacionadas aos dois tipos de CVLs, tendo em vista o processo de formação do elemento nominal que as compõem. No primeiro tipo, o $\mathrm{N}$ é formado diretamente de raiz, Nprimitivo, em apenas uma fase e a leitura obtida, no que diz respeito à completude do evento expresso, é idêntica à leitura da construção com um verbo pleno correspondente (Aquele garoto fez um susto no primo. = Aquele garoto assustou o primo.). Já no segundo tipo, em que temos um Nderivado de verbo, portanto passa por mais de uma fase durante sua derivação sintática, a leitura obtida, no que diz respeito à completude, é aumentativizada. Buscamos explicar que essas diferenças parecem estar relacionadas, nas CVLs com Nderivado, em virtude de terem passado por uma fase verbal, à presença de uma camada funcional de aspecto lexical, que contém, mais precisamente para o que se defende neste trabalho, o traço de duração e o de dinamicidade, e ao fato de as informações não serem acessadas localmente, bem como ao traço aspectual lexical do VL, que contribui para a predicação conjunta.

Referências

ALBA-SALAS, Josep. Light verb constructions in romance: a syntactic analysis. Tese (Ph.D.) Cornell University. Cornell University, 2002.

ALVES, Daniela Almeida. Construções de verbo leve: o elemento nominal e a leitura final. 2016, 239 f. Dissertação de mestrado - Salvador. Universidade Federal da Bahia, 2016.

ARAD, Maya. Locality Constraints on the Interpretation of roots: the case of Hebrews denominal verbs. Natural Language and Linguistic Theory, 21th ed. Netherlands: Kluwer Academic Publishers. 21, 737-778, 2003.

BASÍLIO, Margarida. Estruturas lexicais do português: uma abordagem gerativa. Petrópolis: Vozes, 1980.

BUTT, Miriam. The light verb jungle. Conferência. Harvard/Dudley, 2003.

CHOMSKY, Noam. Derivation by phase. Massachusetts: MIT, 1999.

CYRINO, Sonia; DUARTE, Eugênia; KATO, Mary. Visible subjects and invisible clitics in brazilian portuguese. In: KATO, M.; NEGRÃO, E. (Org.). Brazilian portuguese and the null subject parameter. Madri: Iberoamericana; Frankfurt am Main: Verveurt, 2000. p.55-73.

DUARTE, Inês; GONÇALVES, Anabela; MIGUEL, Matilde; MENDES, Amália; HENDRICKX, Iris; OLIVEIRA, Fátima; CUNHA, Luís Filipe; SILVA, Fátima; SILVANO, Purificação. Light verbs 
features in European Portuguese. Proceedings of the 2nd Interdisciplinary Workshop on the Identification and representation of Verb Features and Verb Classes, Pisa, Italy, 2010.

EMBICK, David. Localism versus globalism in morphology and phonology. Cambridge: MIT Press, 2010.

FIGUEIREDO, Cristina; REIS, Raisa; ALVES, Daniela; FERREIRA, Carla Elisa. Sobre nominalizações em -mento e aspecto lexical. Estudos Linguísticos e literários, 47, 47-67, 2013.

FORTUNATO, Isabella Venceslau. Análise da estrutura argumental do verbo "chegar" em construções com verbo-suporte. Domínios da Linguagem: Revista Eletrônica de Linguística, 3, 1, 3060, 2009.

GONÇALVES, Anabela; OLIVEIRA, Fátima; MIGUEL, Matilde; MENDES, Amália; HENDRICKX, Iris; CUNHA, Luís Filipe; SILVANO, Purificação; DUARTE, Inês; SILVA, Fátima; COLAÇO, Madalena. Propriedades predicativas dos verbos leves dar, ter e fazer: estrutura argumental e eventiva. Disponível em:

$<$ http://www.clul.ul.pt/sectores/gramatica/publicacoes_preplexos/actas_sel.pdf.>. Acesso em: $14 / 02 / 2015$.

GRIMSHAW, Jane; MESTER, Armin. Light verbs and $\theta$-marking. Linguistic Inquiry, v. 19, p. 205232, 1988.

HALLE, Morris; MARANTZ, Alec. Distributed morphology and pieces of inflection. In: HALE, K.;

KEYSER, S. J. (Org.). The view from the Building 20: Essays in honor of Sylvain Bromberger. Cambridge/Massachusetts: MIT Press, p. 111-176, 1993.

HOUAISS, Antônio. Dicionário Eletrônico Houaiss da Lingua Portuguesa. Rio de Janeiro: Objetiva, 2001.

MARANTZ, Alec. Words. (2001) Disponível em: $<$ http://web.mit.edu/ marantz/Public/ALI/Handouts/>.Acesso em: 03/ 08/ 2015.

MARANTZ, Alec. Phases and words. Manuscrito. NYU, 2007.

MARANTZ, Alec. Locality domains for contextual allomorphy across the Interfaces. In: Distributed Morphology Today: morphemes for Morris Halle, ed by Ora Matushansky and Alec Marantz, 95-115. Cambridge, MA: MIT Press, 2013.

MOURA NEVES, Maria Helena de. Estudo das construções com verbo-suporte em português. In: KOCH, I. V. (Org.). Gramática do português falado. Vol VI: desenvolvimentos. Campinas: Unicamp, 1996.

PYLKKÄNEN, Liina. Introducing arguments. 2002. 137 f. Tese (PH.D) - University of Pittsburgh, MIT. Massachussets, 2002.

REIS, Raisa. Os traços de aspecto lexical e as nominalizações em -ção e -mento. Dissertação de Mestrado. Universidade Federal da Bahia, 2016.

ROCHA, Luiz Carlos de Assis. Estruturas morfológicas do português. 2. ed. - São Paulo: WMF Martins Fontes, 2008. 
SCHER, Ana Paula. As construções com o verbo leve "dar" e as nominalizações em -ada no português do Brasil. Tese de doutorado. Universidade Estadual de Campinas, 2004.

SMITH, Carlota. The Parameter of Aspect. 2. ed. Dordrecht: Kluwer Academic Publishers, 1997.

VENDLER, Zeno. Linguistics and Philosophy. Ithaca, New York: Cornell University Press, 1967.

Recebido em: 21 de março de 2018.

Aceito em: 30 de maio de 2018. 